\title{
Identification of Weather Conditions Associated with the Occurrence, Severity, and Incidence of Black Seed Disease of Strawberry Caused by Mycosphaerella fragariae
}

\author{
Odile Carisse ${ }^{\dagger}$ and Vanessa McNealis
}

First author: Agriculture and Agri-Food Canada, 430 Gouin Blvd., Saint-Jean-sur-Richelieu, QC J3B 3E6, Canada; and second author: Department of Mathematics and Statistics, Université de Montréal, André Aisenstadt Building, P.O. Box 6128, Centre-ville Station, Montréal, QC H3C 3J7, Canada.

Accepted for publication 5 September 2017.

\begin{abstract}
Black seed disease (BSD) of strawberry is a sporadic disease caused by Mycosphaerella fragariae. Because little is known about potential crop losses or the weather conditions conducive to disease development, fungicides are generally not applied or are applied based on a preset schedule. Data collected from 2000 to 2011 representing 50 farm-years (total of 186 strawberry fields) were used to determine potential crop losses and to study the influence of weather on disease occurrence and development. First, logistic regression was used to model the relationship between occurrence of BSD and weather variables. Second, linear and nonlinear regressions were used to model the number of black seed per berry (severity) and the

percentage of diseased berries (incidence). Of the 186 fields monitored, 78 showed black seed symptoms, and the number of black seed per berry ranged from 1 to 10 , whereas the percentage of diseased berries ranged from 3 to $32 \%$. The most influential weather variable was total rainfall (in millimeters) in May, with a threshold of $103 \mathrm{~mm}$ of rain (absence of BSD < $103 \mathrm{~mm}<$ presence of BSD). Similarly, nonlinear models with the total rainfall in May accurately predicted both disease severity and incidence $(r=$ 0.94 and 0.97 , respectively). Considering that management actions such as fungicide application are not needed every year in every field, these models could be used to identify fields that are at risk of BSD.
\end{abstract}

Strawberry is an important crop worldwide, and Canada is no exception (Khanizadeh et al. 1993). There are several diseases that affect strawberry roots, foliage, or fruit (Carisse and Maas 2005). The significance of these diseases varies based on the damage they cause, their incidence, and the difficulty and cost of managing them. Common leaf spot of strawberry caused by the ascomycete Mycosphaerella fragariae (Tul. \& C. Tul.) Lindau (= Ramularia tulasnei Sacc.) has had a deleterious impact on a number of strawberry plantings (Plakidas 1965). The first studies on $M$. fragariae were conducted in the 1880s in the United States (Dudley 1889; Trelease 1885). Since then, the disease has been reported in most strawberry-producing countries (Carisse et al. 2000; Paulus 1990; Plakidas 1965). In most strawberry production areas today, common leaf spot is considered a disease of secondary importance that mainly affects leaves (Maas 1987). However, under favorable weather conditions, $M$. fragariae can also cause black seed disease (BSD) of strawberry in susceptible cultivars (Maas 1987).

The most economical and sustainable way to manage $M$. fragariaeinduced diseases is to grow resistant cultivars (Janick and Williams 1959; Nemec 1971). However, the resistant or low-susceptibility cultivars that were widely grown during the 1970s and 1980s were gradually abandoned for cultivars that produced higher yields and better berry color, taste, and shelf life (Carisse and Peyrachon 1999; Delhomez et al. 1995).

Symptoms on leaves first appear as small purple lesions. As the symptoms progress, the lesions increase in size and their center becomes necrotic, with a distinct red border. However, leaf symptoms vary depending on the strawberry cultivar and weather conditions during infection and lesion development (Fall 1951; Maas 1987; Nemec 1972). Symptoms may also develop on petioles

${ }^{\dagger}$ Corresponding author: O. Carisse; E-mail: odile.carisse@agr.gc.ca

(C) 2018 The American Phytopathological Society and calices. BSD symptoms are characterized by the presence of lesions on berries, with each lesion affecting several achenes and the receptacle area surrounding them. The area under and around the infected achenes becomes dark brown, hard, and leathery. The infected achenes turn brownish black. In general, infected berries do not rot, and crop injuries are mostly related to berry quality. However, in eastern Canada, strawberry fruit are frequently marketed as "pick your own," and berries with visible black seed symptoms are often not picked, resulting in direct crop losses.

In northern strawberry-growing areas such as eastern Canada, there are three sources of primary inoculum: conidia overwintering on leaves protected by straw, conidia from overwintering sclerotia, and ascospores produced in perithecia that overwintered in diseased leaves. In the spring, these spores infect strawberry foliage and produce lesions. Secondary spread of the disease is caused by conidia produced on these lesions and dispersed by rain. Production of secondary inoculum can be abundant and, because of the spore dispersal mechanism, high rainfall can result in severe epidemics of both common leaf spot and BSD (Fulton 1958).

Most of what is known about the influence of weather and the host plant on disease development concerns common leaf spot. Controlled studies showed that conidia can germinate at temperatures between 5 and $30^{\circ} \mathrm{C}$ and that the logistic rate of conidia germination was highest at $22.4^{\circ} \mathrm{C}$ (Elliott 1988). No germination was observed when the relative humidity (RH) was $<98 \%$ (Elliott 1988). On leaf lesions, sporulation was observed at $5^{\circ} \mathrm{C}$, and the number of spores per lesions increased as temperature rose from 5 to $20^{\circ} \mathrm{C}$ (Carisse and Peyrachon 1999). On susceptible cultivars, long periods of leaf wetness are required for sporulation. Carisse and Peyrachon (1999) reported that a minimum of $24 \mathrm{~h}$ of leaf wetness was required for sporulation at optimal temperatures but a wetness duration of up to $108 \mathrm{~h}$ was required at suboptimal temperatures. Similarly, prolonged periods of leaf wetness are required for infection. Carisse et al. (2000) reported that infection occurs between 5 and $30^{\circ} \mathrm{C}$. On the most susceptible leaves ( 7 days old), the number 
of lesions increased gradually as the temperature rose from 5 to $25^{\circ} \mathrm{C}$ and then decreased abruptly as it rose from 25 to $30^{\circ} \mathrm{C}$. Regardless of the temperature, a minimum of $12 \mathrm{~h}$ of leaf wetness was required for infection and only moderate infection (1.2 to 3.7 lesions $/ \mathrm{cm}^{2}$ of leaf) was observed when leaf wetness duration was less than $48 \mathrm{~h}$ (Carisse et al. 2000). Information on black seed development is sparse. During bloom, M. fragariae probably colonizes the strawberry flower stigma and then moves on to the achene, eventually infecting the surrounding receptacle tissues. Not all possible infection pathways and conditions favoring stigma infection are known (Maas 1987; Plakidas 1934).

In several strawberry production areas, it is recommended that common leaf spot be controlled with applications of protective fungicides (CPVQ 1992; OMAFRA 1996). In plantings with Junebearing susceptible cultivars and where strawberry fruit are mostly sold under the "pick your own" system, it is recommended that fungicides be applied once 3 to 4 weeks after planting and two more times during the growing season (CPVQ 1992; OMAFRA 1996). During the production years, the Quebec protection guide (CPVQ 1992) recommends applying the first spray in early spring and subsequent sprays when the first flowers appear, additional sprays being applied when conditions are favorable for disease development. In practice, given that consumers are reluctant to pick strawberry fruit in fields infected by common leaf spot and that the conditions favorable to disease development are not well defined, growers tend to apply fungicides on a regular basis, regardless of the level of risk of infection or potential crop losses. Most of these fungicides act against not only common leaf spot but also other foliar diseases such as leaf scorch (caused by Diplocarpon earliana), Phomopsis leaf blight (caused by Phomopsis obscurans), or powdery mildew (Podosphaera aphanis), and berry diseases such as gray mold (Botrytis cinerea). Considering the high level of fungicide resistance in several plant pathogens, including B. cinerea populations (Gossen et al. 2014), it is important to limit the use of fungicides to fields with a moderate to high risk of crop losses.

BSD is sporadic and probably over-treated. However, because little is known about potential crop losses (Dale and Fulton 1957; Marcoux 1996) or the influence of weather on BSD, fungicide needs are not well defined, resulting in either inadequate control or waste of fungicides. Consequently, the general objective of this study was to determine the seasonal weather conditions that favor BSD. More specifically, the objectives of this work were to identify weather variables associated with occurrence, severity, and incidence of BSD and to model the influence of weather on the development of the disease.

\section{MATERIALS AND METHODS}

Data collection. The data were collected from 2000 to 2011 at the Agriculture and Agri-Food Canada experimental farms located in L'Acadie and Frelighsburg and at commercial farms located in the Montérégie strawberry-growing area in southeast Montreal. Fifty farm-years covering 186 fields were assessed for BSD severity and incidence (not all fields were assessed every year). BSD data were collected in fields of 0.5 to 1.0 ha planted with the Junebearing cultivars Chambly, Kent, and Jewel during the first or second year of production. Chambly is considered moderately susceptible to M. fragariae, whereas Jewel and Kent are considered highly susceptible (Delhomez et al. 1995). In each field that was assessed, 100 randomly selected berries, each one from a different plant also selected randomly, were examined for black seed 2 weeks before harvest. This date was chosen because it is easier to detect black seed when the berries are not completely red. On diseased berries, the number of black seed (lesions) per berry was counted. The data were expressed as occurrence of black seed ( 0 or 1 for black seed being absent or present, respectively), severity expressed as number of black seed per berry, and incidence expressed as percentage of berries with black seed.
The weather data were obtained from Environment Canada weather stations located at the experimental farms and stations located at or within $3 \mathrm{~km}$ of the commercial farms. The weather data were hourly temperature $\left({ }^{\circ} \mathrm{C}\right), \mathrm{RH}$ (percent), and rainfall (millimeters). All weather variables were summarized over a day. Air temperature $(\mathrm{T})\left({ }^{\circ} \mathrm{C}\right)$ and $\mathrm{RH}$ (percent) variables were expressed as daily mean (T and RH), minimum (TMIN and RHMIN), and maximum (TMAX and RHMAX); rainfall was expressed as accumulated rainfall (RAIN in millimeters), rainfall duration (DRAIN, hours), and number of days with rainfall (DAYRAIN in days). Information from the scientific literature was used to construct weather variables that could be useful in predicting the risk of BSD (Carisse and Peyrachon 1999; Carisse et al. 2000; Elliott 1988; Fall 1951). These weather variables are mean T during rainfall (TRAIN, ${ }^{\circ} \mathrm{C}$ ), duration (hours) when $\mathrm{RH} \geq 90 \%$ (DRH90, hours), mean $\mathrm{T}\left({ }^{\circ} \mathrm{C}\right.$ ) when $\mathrm{RH} \geq 90 \%$ (TRH90, ${ }^{\circ} \mathrm{C}$ ), duration (hours) when $\mathrm{RH} \geq 95 \%$ (DRH95, hours), mean $\mathrm{T}\left({ }^{\circ} \mathrm{C}\right.$ ) when $\mathrm{RH} \geq 95 \%$ (TRH95, ${ }^{\circ} \mathrm{C}$ ), duration (hours) when $\mathrm{T}>10^{\circ} \mathrm{C}$ (DT $>10$, hours) duration (hours) when $\mathrm{T}>20^{\circ} \mathrm{C}$ (DT $>20$, hours), and duration (hours) $\mathrm{T}>30^{\circ} \mathrm{C}$ (DT $>30$, hours). These variables were calculated for May, June, and May and June combined (Table 1).

Modeling BSD occurrence using logistic regression analysis. A simple random sample of 10 field-years was extracted from the complete data set of 50 field-years using PROC SURVEYSELECT in the SAS software program (version 9.4; SAS Institute Inc., Cary, NC). These 10 field-years and associated field observations were set aside to be used for model validation.

To predict occurrence (presence of absence) of BSD, logistic regression was used to model the relationship between occurrence in its binary form and weather variables. More specifically, the purpose of this analysis was to construct a parsimonious, biologically rational logistic model with good prediction accuracy according to the following structure:

$$
\ln \{p(x) /[1-p(x)]\}=\alpha+\beta^{\prime} x
$$

where $x$ is a vector of $p$ regressors, $p(x)$ is the probability of observing a disease outbreak, which depends on the values of regressors $x, \alpha$ is the intercept parameter (the value of $\ln \{p(x) /[1-$ $p(x)]\}$ when $x=0$ ), and $\beta^{\prime}$ is a transposed vector of $p$ coefficient parameters corresponding to the $p$ regressors (Weisberg 2014).

To avoid redundancy, given that the disease occurrence value and weather observations were the same for all fields from a given fieldyear, the training data set containing observations from 40 fieldyears was used for model fitting. Preliminary univariate analyses were conducted to identify weather variables that may be involved in occurrence of BSD. Box plots of weather variables were examined to assess potential separation between epidemic and nonepidemic field-years. In addition, Kendall correlation coefficients (KCC) were computed to detect collinearity between weather variables $(\mathrm{KCC}>0.30)$.

The logistic analysis was performed using PROC LOGISTIC in SAS. Univariate logistic regression models predicting the binary representation of BSD occurrence were computed for all 52 possible predictors: 51 weather variables $+\log$ total rainfall during the month of May $(\log [$ MAYRAIN]). Few weather variables caused complete or quasicomplete separation between BSD occurrence and nonoccurrence field-years, leading to numerical problems. In those cases, Firth's bias-reducing penalized likelihood approach was employed to compute maximum-likelihood parameter estimates in SAS. A preliminary selection of candidate regressors was conducted using the thumb rule based on likelihood ratio test statistics as follows. The weather variables whose univariate logistic regressions had a likelihood ratio $P$ value $<0.25$ were further considered in model selection. Considering only this subset of regressors, final candidate models were obtained by using the bestsubsets routine with the $\chi^{2}$ score criterion. Models of one to three predictors were evaluated based on their prediction accuracy. 
TABLE 1. Weather variables used in modeling black seed disease (caused by Mycosphaerella fragariae) occurrence, severity, and incidence, together with the likelihood ratio test statistic $\chi^{2}$ and corresponding $P$ value (in parentheses) that was used to select a subset of candidate predictors for logistic models and the Kendall correlation coefficient (KCC) with either the positive mean number of black seed per berry (BS) or the positive percentage of diseased berries (Pdis) that was used to identify variables of potential value in truncated normal hurdle models

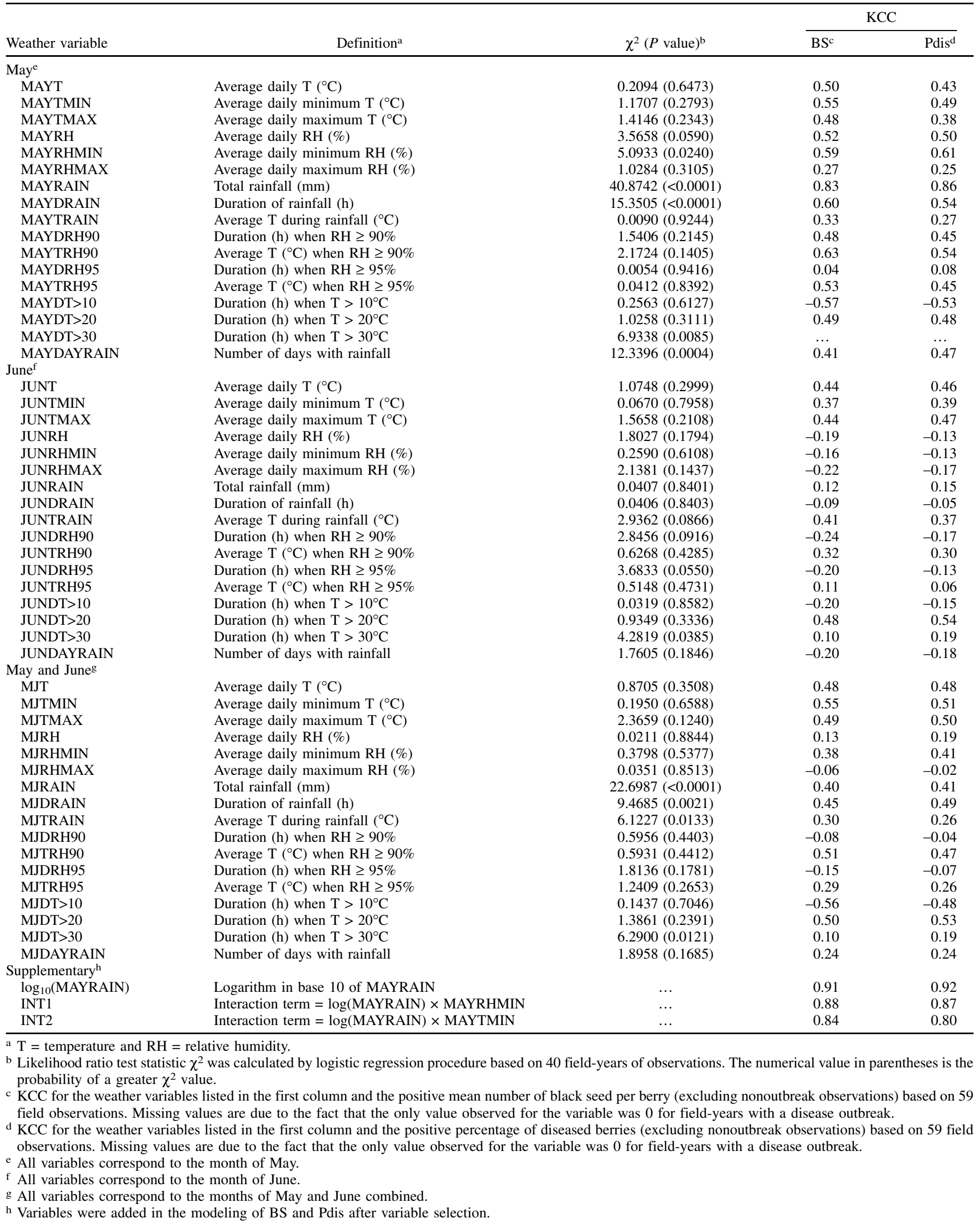


Although these models were fitted on the training data set containing the 40 summarized field-years of observations, they were scored on the training set containing all 148 field observations. Models that included highly intercorrelated predictors were excluded from the selection.

Given the values of the model regressors, a logistic model would predict the probability of BSD occurrence $(\theta(x)$ in equation 1$)$. Therefore, the classification of a field-year as a BSD occurrence year depends on a threshold probability $\left(p_{c}\right)$, which the predicted probability exceeds in the case of a disease occurrence prediction. By default, SAS predicts an occurrence when the predicted probability $\theta(x)$ is $>0.5$, which may not necessarily yield the highest sum of sensitivity and specificity. For each model selected, the critical probability $p_{c}$ was determined by calculating sensitivity and specificity for a range of possible values of $p_{c}$ and choosing the one that provided the best compromise between specificity and sensitivity. Generally, keeping the default $p_{c}=0.5$ worked well for this purpose, because the priority was to correctly predict nonevents.

Modeling BSD severity and incidence using hurdle models. Preliminary descriptive analyses showed that the distributions of the mean number of black seed per berry and percentage of diseased berries were both highly right-skewed, with a large proportion of 0 values. Thus, commonly used linear regression was not appropriate for these data. Instead, truncated normal hurdle models were considered. The density of the truncated normal hurdle model was suggested by Cragg (1971). It is a two-stage model that first uses logistic regression to model the probability that the dependent variable is positive and then uses ordinary linear regression to model the positive values of the dependent variable. In other words, the first stage of the model decides whether there is a disease outbreak. In the event of a positive, the second stage assesses its severity. Let $y$ be a dependent variable (either the mean number of black seed severity or incidence), $x_{1}$ a set of weather variables, and $w$ a binary variable taking the value 1 when $y$ is positive and the value 0 when it is not. Then, the probability of observing $w=1$ is equal to $p\left(x_{1}\right)$, modeled by a logistic model (equation 1). It can be expressed as follows:

$$
P\left(w=1 \mid x_{1}\right)=\left\{1 /\left[1+\exp \left(-\alpha_{1}-\beta_{1}^{\prime} x_{1}\right)\right]\right\}
$$

where $\alpha_{1}$ is an intercept parameter and $\beta^{\prime}{ }_{1}$ is a transposed vector of $p$ coefficients corresponding to the $p$ regressors $x_{1}$. If we define $y^{*}$ as being equal to $y$ if $y>0$ and missing if it is not, then we can simply fit a linear regression model with $y^{*}$ as a dependent variable and a different set of predictors for $x_{2}$ :

$$
y *=\alpha_{2}+\beta_{2}^{\prime} x_{2}+e
$$

where $\alpha_{2}$ is an intercept parameter, $\beta_{2}^{\prime}$ is a transposed vector of $p$ coefficient parameters associated with the $p$ predictors $x_{2}$, and $e$ is a random effect. It should be noted that these parameters may vary freely from those of the logistic regression component of the model (Min and Agresti 2002). Furthermore, different covariates can be used in the two components of the truncated normal hurdle model. The two components of the model are meant to be fitted separately. An underlying assumption of this model is that $y^{*}$ and $w$ are independent and conditional on predictor variables $x$. This way, the expected value of $y$ conditional on $x$ is simply equal to the product of $P\left(w=1 \mid x_{1}\right)$ and the expected value of $y^{*}$ conditional on $x$, given that the expected value of $y$ is 0 if $w=0$.

The training data set containing all 148 field observations was used to model both disease severity and incidence, because the two dependent variables showed variability within the same field-year. The first part of the truncated model was already covered, given that it could be any of the previously fitted logistic models. The positive versions of the two dependent variables were added as new variables to the data set to be modeled separately. For instance, if the mean number of black seed was $>0$, the positive mean number of black seed would take the same value; if not, its value would be missing.
To identify weather variables associated with the positive mean number of black seed per berry and the positive percentage of diseased berries, a nonparametric correlation analysis was performed. Because we wanted a measure of correlation that could account for any kind of monotonic relationship, a KCC was used to assess the strength of the relationships. Groups of variables of the same kind were formed. For each period of interest (namely May, June, and May and June combined), there were four groups: temperature variables, humidity variables, rainfall variables, and composite variables. We then selected a subset of candidate predictors by choosing the most correlated variable within each group where the absolute value of the KCC was $>0.45$. This threshold was chosen with the intention of substantially reducing the set of candidate variables, given that many of them were constructed and, therefore, intercorrelated. This process reduced the set of candidate variables to 10 for the positive mean number of black seed per berry and 11 for the positive percentage of diseased berries.

Variables identified in the correlation analysis were further analyzed in the development of the linear models. To assess the individual linear relationships between either the positive mean number of black seed per berry or the positive percentage of diseased berries and each candidate predictor variable, univariate linear regression models were computed. In some cases, logarithmic transformation of variables was added to the subset of candidate predictors. The best-subsets selection procedure implemented in the REG procedure in SAS was used as a guide to identify the variables that produced the highest adjusted coefficient of determination $\left(R_{\mathrm{adj}}^{2}\right)$ in models with one, two, or three predictor variables. For both dependent variables, five weather variables that produced the highest accuracy in simple or multiple linear regressions were considered for the last step of model selection, and their two-way interaction terms were calculated as well. Models with one, two, and three predictor variables were evaluated based on $R^{2}$. Except for models including interaction terms, we made sure that the variables within the same model had variance inflation factors between 0 and 10 , which correspond to low to moderate multicollinearity (Weisberg 2014). Also, the concordance correlation coefficient (CCC) was used as a measure of model accuracy. It was calculated as $\mathrm{CCC}=r \times C_{b}$, where $r$ is the Pearson product-moment correlation between observed and predicted values and $C_{b}$ is a bias coefficient representing the deviation of the best-fit line from the concordance line (perfect agreement between observed and predicted values), which is a straight line with an intercept of 0 and a slope of 1 (Madden et al. 2007).

Because the linear models, including MAYRAIN and $\log$ (MAYRAIN), defied linear regression hypotheses, given that the plots of residuals suggested an incorrect mean function, a nonlinear model with the predictor MAYRAIN was also developed to model the second stage of the hurdle model. To do so, a mean function (Noll et al. 1984; Parks 1982; Weisberg 2014) was used:

$$
E(y \mid x)=\theta_{1}+\theta_{2}\left[1-\exp \left(-\theta_{3} x\right)\right]
$$

where $y$ is either the number of black seed per berry or the percentage of diseased berries, $x$ is a predictive weather-based variable, $\theta_{1}$ is the intercept parameter, $\theta_{2}$ is the difference between the horizontal asymptote and the intercept, and $\theta_{3}$ is a rate parameter.

This mean function was fitted to the data using PROC NLIN in SAS. The NLIN procedure requires a range of possible values for each parameter to perform a grid search. The parameter values were estimated by inspecting the scatter plots. To facilitate the estimation of the parameters, we first performed a translation of the plots by subtracting 100 from MAYRAIN, because it was the approximate starting point for positive values of the mean number of black seed or the percentage of diseased berries. It was easy to approximate $\theta_{1}$ and $\theta_{2}$ by looking at the plots. A range of starting values for rate $\theta_{3}$ was determined by substituting the approximate values of $\theta_{1}$ and 
$\theta_{2}$ and one observed coordinate (MAYRAIN, $y^{*}$ ) in the following equation:

$$
\theta_{3}=\left\{-\ln \left[\left(\theta_{1}=\theta_{2}-y *\right) / \theta_{2}\right]\right\} /(\text { MAYRAIN }-100)
$$

Model validation. The linear and nonlinear models were fitted to the validation data set, which had not been used for model development. This data set covered 10 field-years and included 38 field observations. Models were evaluated based on the correlation between observed and predicted values I and the CCC.

\section{RESULTS}

Of the 186 fields monitored, 78 showed BSD (Fig. 1). When black seed was present, the number of black seed per berry ranged from 1 to 10 , while the percentage of diseased berries ranged from 3 to $32 \%$ (Fig. 1). For all field-years, the mean daily temperature in May ranged from 10.44 to $16.11^{\circ} \mathrm{C}$ and the amount of rainfall ranged from 36.0 to $265.4 \mathrm{~mm}$. In June, the mean daily temperature ranged from 15.48 to $21.36^{\circ} \mathrm{C}$ and the amount of rainfall ranged from 51.15 to $273.0 \mathrm{~mm}$. Box plots for the seven weather variables selected by the best-subsets logistic regression procedure as potential predictors of BSD outbreaks are presented in Figure 2.

Modeling BSD outbreaks using logistic regression analysis. Likelihood ratio statistics for all 51 variables studied in univariate logistic regression analysis are shown in Table 1 . Twenty-five variables that were individually related to BSD outbreaks and nonoutbreaks across the 40 farm-years were identified. The likelihood ratio test $P$ value for these 25 variables ranged from $<0.0001$ to 0.2391 . The variable with by far the highest likelihood ratio test statistic was MAYRAIN (Table 1). This variable, along with MAYDT $>30$, allowed for complete separation between occurrence and nonoccurrence field-years, leading to numerical problems in the calculation of maximum-likelihood estimates. In general, variables related to rainfall for the periods of May and May and June combined had higher likelihood ratio test statistics (Table 1).

The best-subsets automatic procedure based on the subset of 25 variables was used to select the final logistic models with one, two, and three predictors. The models were ranked by $\chi^{2}$ score statistic. Some weather variables were highly intercorrelated $(\mathrm{KCC}>0.30)$ and, therefore, could not be included together in a logistic model. For instance, the three variables most related to BSD outbreaks-MAYRAIN, total rainfall in May and June (MJRAIN), and May duration of rainfall (MAYDRAIN) - were known to be highly intercorrelated. Four other variables were identified by the procedure as having an effect on BSD outbreaks and nonoutbreaks in multiple logistic models. Two of these variables, May average temperature when $\mathrm{RH} \geq 90 \%$ (MAYTRH90) and June duration of rainfall (JUNDAYRAIN), did not have significant $(P<0.05)$ individual relationships according to the likelihood ratio test. The best model with two predictors consisted of MAYRAIN and average temperature during rain in May and June (MJTRAIN), and the KCC between these two variables was -0.25 . The model that included MAYRAIN, May average daily minimum RH (MAYRHMIN), and JUNDAYRAIN had the highest $\chi^{2}$ score statistic of all three-variable models and was also the only three-variable model with low to moderate multicollinearity. The best multiple logistic models always included MAYRAIN. Variables related to rainfall provided the greatest degree of separation of occurrence and nonoccurrence field-years (Fig. 2).

Eight logistic models (equation 1) were selected and fitted to the 40-field-year data (training data set). Predicted values were computed based on a critical probability $p_{c}=0.50$. When applied to the training data set, including specific field observations, the prediction accuracy of the models was 76.4 to $98.0 \%$ (Table 2). All of the models significantly $(P<0.05)$ predicted occurrence and nonoccurrence field-years. Models A, E, F, and H correctly classified $96.6 \%$ of the 148 field observations, whereas model D correctly classified $98.0 \%$ of the cases. More specifically, models A, E, F, and $\mathrm{H}$ misclassified the same field-year, which had five specific field observations. Model D also misclassified one field-year but it was a different one that had three specific field observations. Although all five of these models included MAYRAIN as a predictor, one of them used MAYRAIN alone, with a prediction accuracy of $96.6 \%$. Models A, E, F, and H correctly predicted $100 \%$ of nonoccurrence field observations (specificity) but correctly classified $91.5 \%$ of BSD outbreaks. Model D showed a slight improvement in sensitivity, with $94.9 \%$ of BSD outbreaks correctly classified. The remaining models (namely, B, C, and G) did not include predictor variable MAYRAIN. When scored on the training data set containing all 148 field observations, these three models had a prediction accuracy of 76.4 to $86.5 \%$. They had lower values for sensitivity and specificity than did models A, D, E, F, and H. Four logistic models (A, C, D, and G) were rearranged algebraically to solve for threshold values given by weather variables. The following equations were obtained:

$$
\begin{aligned}
\text { MAYRAIN } & =\left\{\ln \left[p_{c} /\left(1-p_{c}\right)\right]-\alpha\right\} / \beta_{1} \\
\text { MAYDRAIN } & =\left\{\ln \left[p_{c} /\left(1-p_{c}\right)\right]-\alpha\right\} / \beta_{1} \\
\text { MAYRAIN } & =\left\{\ln \left[p_{c} /\left(1-p_{c}\right)\right]-\alpha-\beta_{2} \text { MJTRAIN }\right\} / \beta_{1} \\
\text { MAYDRAIN } & =\left\{\ln \left[p_{c} /\left(1-p_{c}\right)\right]-\alpha-\beta_{2} \text { MJTRAIN }\right\} / \beta_{1}
\end{aligned}
$$

with $\beta$ estimates given in Table 2 for each model. For equation 6 , with a critical probability $p_{c}=0.50$, a MAYRAIN value $>102.9$
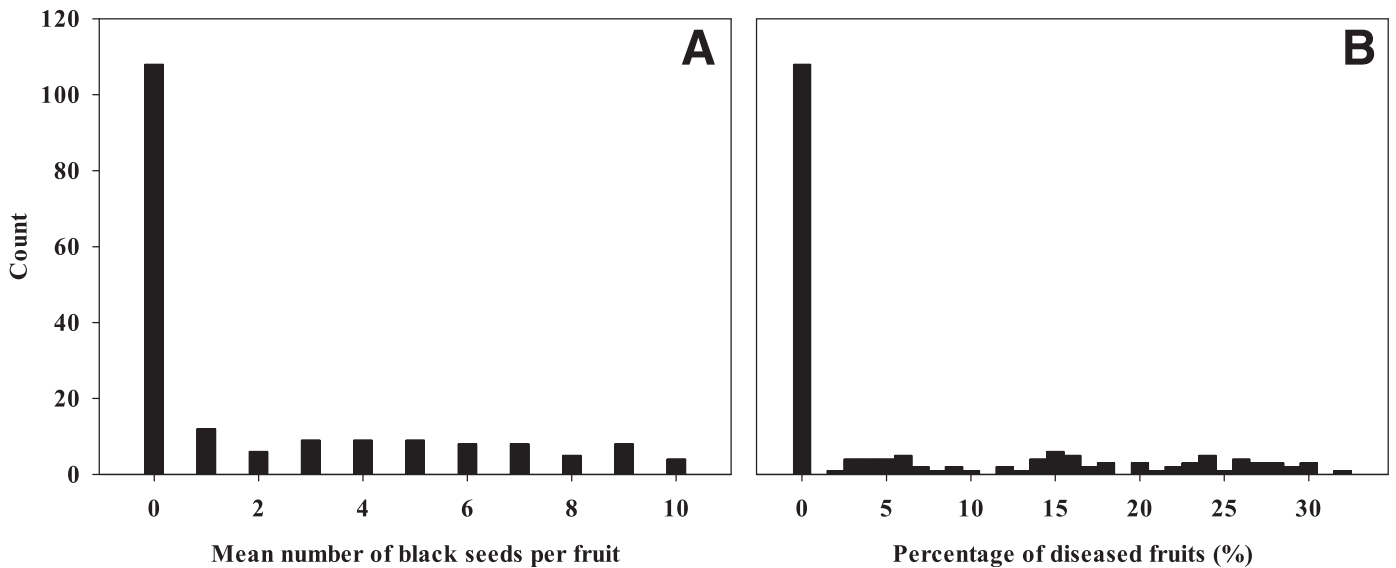

Fig. 1. Histograms for the frequency of $\mathbf{A}$, mean number of black seed per berry and $\mathbf{B}$, percentage of diseased berries. Data were collected in 186 strawberry fields between 2000 and 2011 . 
indicated an occurrence (Fig. 3) whereas, for equation 7, an occurrence was predicted when a MAYDRAIN value $>89.9$ was observed. Decision thresholds for equations 8 and 9 are combinations of two variables that may be represented graphically by sloped straight lines passing through a scatterplot of occurrence and nonoccurrence field-years.

Modeling BSD severity and incidence using hurdle models. The KCC between the 52 weather variables and either the positive mean number of black seed (BS) or the positive percentage of diseased berries (Pdis) are shown in Table 1. Except for supplementary variables, which were added after variable selection, the correlations of these variables were analyzed to select a preliminary subset of candidate regressors for the second stage of the hurdle models. Nonparametric correlation analysis helped identify 10 and 11 variables that could be useful for predicting BS and Pdis, respectively. Nine selected variables were common to both
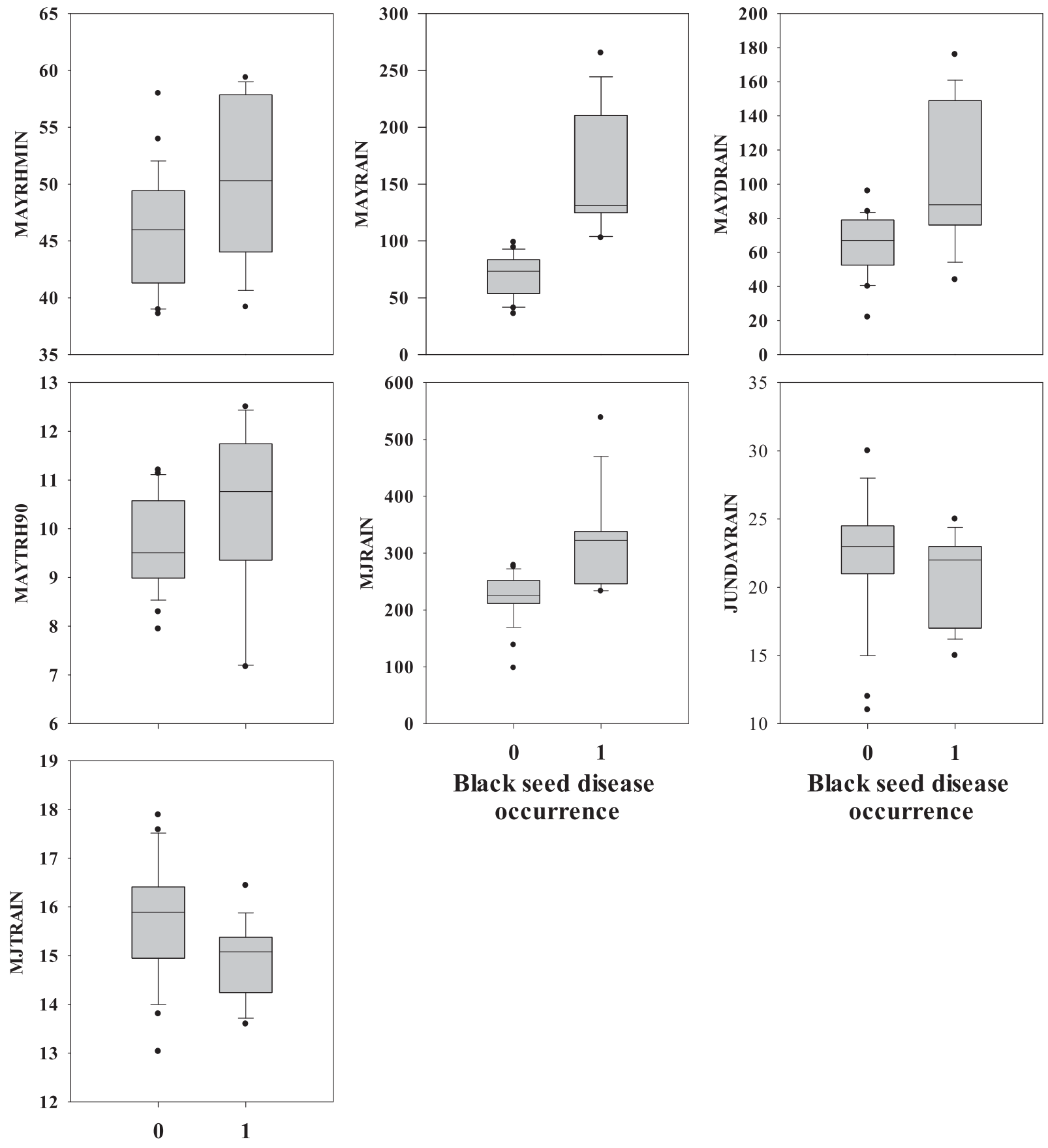

\section{Black seed disease occurrence}

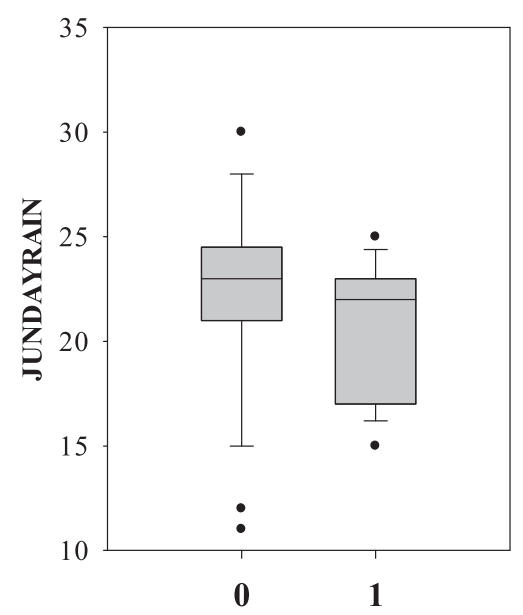

Black seed disease
occurrence

\section{Black seed disease occurrence}

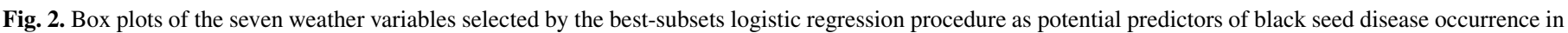

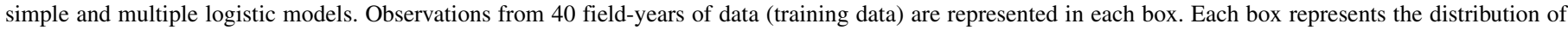

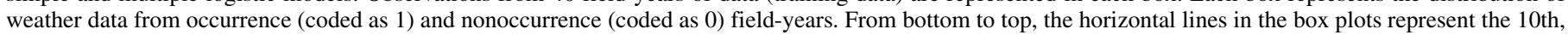

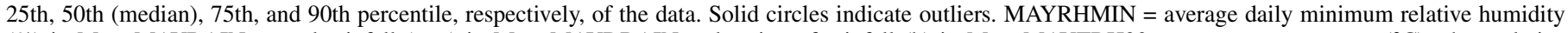

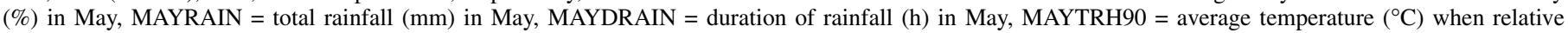

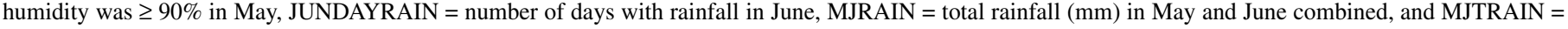
average temperature during rainfall $\left({ }^{\circ} \mathrm{C}\right)$ in May and June combined. 
severity variables: namely, MAYTMIN, MAYRHMIN, MAYRAIN, MAYTRH90, MAYDT>10, JUNDT>20, MJTMIN, MJDRAIN, and MJTRH90. The variable MJDT $>10$ was also selected for BS while JUNTMAX and MJDT>20 completed the set of candidate predictors for Pdis. The absolute value of the KCC of selected variables for models with BS and Pdis was 0.45 to 0.83 and 0.47 to 0.86 , respectively. In both cases, the most correlated variable was MAYRAIN.

After investigating the univariate linear regressions, it was apparent that the relationships between MAYRAIN and either BS or Pdis were strong but not linear. In an attempt to linearize the relationships, we added a log-transformed version of this variable, $\log _{10}$ (MAYRAIN), which had KCC of 0.91 and 0.92 with BS and Pdis, respectively.

The best-subsets routine initially identified six variables as individually or jointly having a strong relationship with BS according to $R^{2}$ (Table 3 ). The first was $\log _{10}$ (MAYRAIN), followed by MAYRAIN, MAYRHMIN, MAYDT $>10$, MAYTMIN, and MAYTRH90. The variable MAYDT $>10$ was ultimately rejected after we noticed that its estimated coefficient was not significant in a linear regression with $\log _{10}$ (MAYRAIN), even when a two-way interaction was included, unlike the similar variable MAYTMIN (Table 3). The selection for Pdis consisted of almost the same five variables, except for MJDT>20, which took the place of MAYTRH90, because it led to a substantial difference in $R^{2}$ in simple and multiple linear models (Table 4). The variable MJDRAIN was dropped from consideration because it was highly correlated with MAYRAIN. Within the final subsets of candidate predictors, there were still correlated variables. For instance, in the modeling of BS, variables MAYTMIN and MAYTRH90 had a KCC of 0.69 and, therefore, could not be used together in a multiple linear model. The final step in modeling BS and Pdis variables consisted of fitting linear models (equation 3 ) containing one to three of the five selected variables and their two-way interactions. The best models for predicting BS and Pdis according to $R_{\mathrm{adj}}^{2}$ are shown in Table 3 and Table 4, respectively. When these models were applied to the training data set, the best fits were obtained for the models containing $\log _{10}$ (MAYRAIN) as a predictor variable (BS1 and BS6), with a Pearson correlation coefficient I between observed and predicted values of 0.91 to 0.93 . However, parabolic shapes were detected in the residuals of the models that included $\log _{10}$ (MAYRAIN) as a predictor, indicating that the linear model was not appropriate for these data. For the number of black seed per berry, the $\mathrm{CCC}$ for all models fitted to the training data set was 0.70 to 0.92 but, when fitted to the validation data set, the values were 0.04 to 0.65 , suggesting poor accuracy, except for models with $\log _{10}$ (MAYRAIN), for which the CCC was 0.93. For the percentage of diseased berries, the CCC for all models fitted to the training data set was 0.70 to 0.96 but, when fitted to the validation data set, the values were -0.06 to 0.71 , suggesting poor accuracy.

Alternatively, a nonlinear regression model (equation 4) was considered for describing the relationship between MAYRAIN and either BS or Pdis. For BS, possible values supplied in PROC NLIN for $\theta_{1}, \theta_{2}$, and $\theta_{3}$ ranged from 0 to 2,8 to 10 , and 0 to 1 , respectively. For Pdis, starting values were 0 to 2,30 to 33 , and 0 to 1 for $\theta_{1}, \theta_{2}$, and $\theta_{3}$, respectively. The estimates that jointly produced the lowest sum of squares for both models can be found in Table 5 . When fitted to the training data, the Pearson correlation coefficient I between

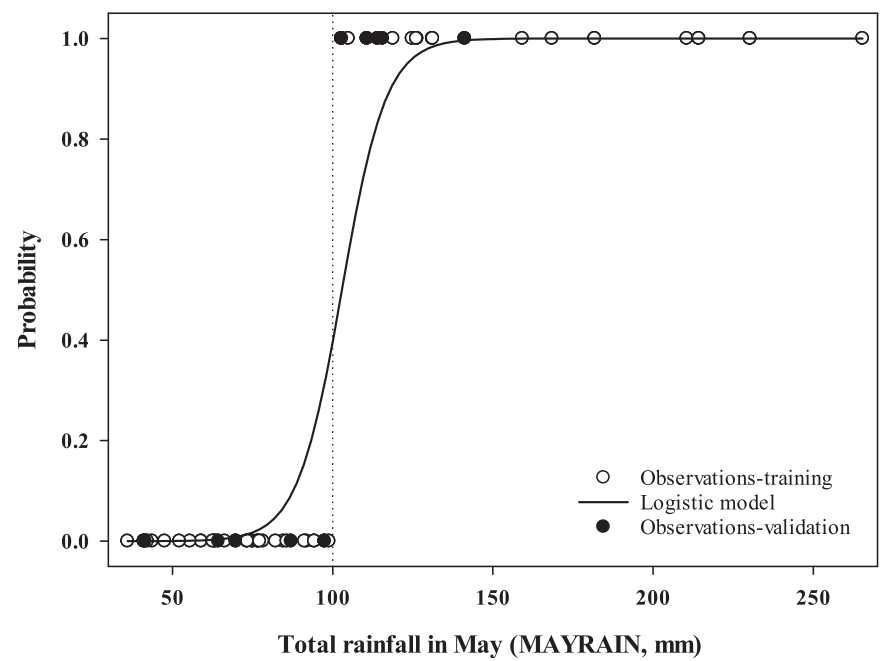

Fig. 3. Relationship between the probability of black seed disease occurrence and total rainfall $(\mathrm{mm})$ in May (MAYRAIN). The curve plotted is $p=1 /[1+$ $\exp \left(-\alpha-\beta_{1}\right.$ MAYRAIN $\left.)\right]$, where $p$ is the probability of black seed disease outbreak, represented on the vertical axis, and $\alpha$ and $\beta_{1}$ are estimated coefficients for logistic model A. Observations from 40 and 10 field-years occurrences (coded as 1) and nonoccurrences (coded as 0) are represented by empty and filled circles, respectively.

TABLE 2. Estimated parameters and corresponding standard errors (in parentheses) of eight logistic models (LM) (equation 1) used to classify field-years for black seed disease (Mycosphaerella fragariae) occurrence, together with prediction accuracy, sensitivity, and specificity

\begin{tabular}{|c|c|c|c|c|c|c|c|c|}
\hline \multirow[b]{2}{*}{$\mathrm{LM}$} & \multirow[b]{2}{*}{ Variables $^{\mathrm{b}}$} & \multicolumn{4}{|c|}{ Estimated regression parameter (corresponding standard errors) ${ }^{\mathrm{a}}$} & \multicolumn{3}{|c|}{ Percentage } \\
\hline & & $\alpha$ & $\beta_{1}$ & $\beta_{2}$ & $\beta_{3}$ & $\mathrm{PA}^{\mathrm{c}}$ & $\operatorname{Sen}^{\mathrm{d}}$ & $\mathrm{Spe}^{\mathrm{e}}$ \\
\hline$A^{f}$ & MAYRAIN & $-4.9047(5.7097)$ & $0.1449(0.0576)$ & $\ldots$ & $\ldots$ & 96.6 & 91.5 & 100.0 \\
\hline B & MJRAIN & $-12.0333(3.8538)$ & $0.0442(0.0148)$ & $\ldots$ & $\ldots$ & 81.8 & 64.4 & 93.3 \\
\hline$D^{f}$ & MAYRAIN + MJTRAIN & $2.1287(12.0588)$ & $0.0953(0.0357)$ & $-0.7985(0.7676)$ & $\ldots$ & 98.0 & 94.9 & 100.0 \\
\hline$E^{f}$ & MAYRAIN + MAYTRH90 & $-7.9591(6.3962)$ & $0.1065(0.0370)$ & $-0.3433(0.5724)$ & $\ldots$ & 96.6 & 91.5 & 100.0 \\
\hline $\mathrm{F}^{\mathrm{f}}$ & MAYRAIN + MAYRHMIN & $-1.0282(4.5210)$ & $0.0616(0.0200)$ & $-0.1246(0.1163)$ & $\ldots$ & 96.6 & 91.5 & 100.0 \\
\hline
\end{tabular}

${ }^{a}$ In accordance with equation 1, estimates of the parameters $\alpha$, the intercept parameter, and $\beta$, the coefficient parameters for the weather variables given in the second column.

${ }^{\mathrm{b}}$ Logistic regression models were developed based on 40 farm-years. MAYRAIN = May total rainfall, MJRAIN = May and June total rainfall, MAYDRAIN = May duration of rainfall, MJTRAIN = May and June average temperature during rainfall, MAYTRH90 = May average temperature when relative humidity $(\mathrm{RH})$ $\geq 90 \%$, MAYRHMIN = May minimum RH, and JUNDAYRAIN = number of days with rainfall. The probability of a greater $\chi^{2}$ for a score test was $P<0.0001$ for models A, D, E, F, and $\mathrm{H}$ and $P=0.0001,0.0003$, and 0.0003 for models $\mathrm{B}, \mathrm{C}$, and $\mathrm{G}$ respectively.

${ }^{c}$ Predicted accuracy (PA) as a percentage of correctly classified cases of outbreaks and nonoutbreaks (outbreak $=$ at least one case of black seed disease). Predicted accuracy was calculated with 148 field observations. An observation was classified as an outbreak if predicted probability $p(x)$ (equation 1$)$ was $>0.5$.

d Sensitivity (Sen) as a percentage of correctly classified outbreaks out of 148 field observations. An observation was classified as an occurrence if predicted probability $p(x)$ (equation 1 ) was $\geq 0.5$.

e Specificity (Spe) as a percentage of correctly classified nonoccurrence out of 148 field observations. An observation was classified as a nonoccurrence if predicted probability $p(x)$ (equation 1 ) was $<0.5$.

f Models fitted using Firth's penalized logistic regression option in logistic procedure because of numerical problems.

$\mathrm{g}$ Model not selected by the best-subsets procedure but included for comparison purposes. 
observed and predicted values was 0.94 and 0.97 and the $\mathrm{CCC}$ was 0.93 and 0.97 for the model predicting BS and the model predicting Pdis, respectively (Fig. 4). When these models were fitted to the validation data sets, $r$ between observed and predicted values was 0.94 and 0.94 and the CCC was 0.90 and 0.91 for the model predicting BS and the model predicting Pdis, respectively (Fig. 4).

\section{DISCUSSION}

The Strawberry Disease and Pest Compendium (Maas 1987) describes more than 97 diseases, 33 of which cause damage to fruit. Because of the absence of host resistance and potential crop losses, gray mold is generally considered the most damaging strawberry fruit disease. In general, BSD is not considered an important disease. However, this study found that BSD was present in $42 \%$ of the fields surveyed over a 12-year period across 50 farm-years. When the disease was present, the number of black seed per berry ranged from 1 to 10 and the percentage of diseased berries was 3 to $32 \%$. Assuming that berries with black seed symptoms are considered unmarketable due to their appearance and are not picked by pickers or consumers, these results suggest that this disease is not of secondary importance and should be considered more seriously during the development of disease management programs. Information on the epidemiology of BSD is sparse, and it is generally assumed that the conditions that are favorable for leaf spot development are also conducive to BSD.

TABLE 3. Estimated parameters and corresponding standard errors (in parentheses) of 11 models (equation 3) describing the effects of weather variables on the positive mean number of black seed per berry (Mycosphaerella fragariae)

\begin{tabular}{|c|c|c|c|c|c|c|c|c|}
\hline \multirow[b]{2}{*}{ Model } & \multirow[b]{2}{*}{ Variable $^{\mathrm{b}}$} & \multicolumn{4}{|c|}{ 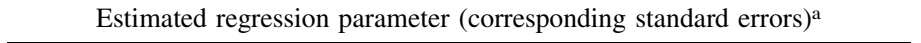 } & \multirow[b]{2}{*}{$r^{\mathrm{c}}$} & \multicolumn{2}{|c|}{$\mathrm{CCC}$} \\
\hline & & $\alpha$ & $\beta_{1}$ & $\beta_{2}$ & $\beta_{3}$ & & $\operatorname{TrD}^{\mathrm{d}}$ & $\mathrm{Val}^{\mathrm{e}}$ \\
\hline BS1 & $\log$ (MAYRAIN) & $-35.8423(2.5824)$ & $19.0469(1.1803)$ & $\ldots$ & $\ldots$ & 0.91 & 0.90 & 0.93 \\
\hline BS2 & MAYRAIN & $-1.8928(0.5900)$ & $0.0480(0.0035)$ & $\ldots$ & $\ldots$ & 0.87 & 0.86 & 0.43 \\
\hline BS4 & MAYTMIN & $-4.1971(1.0668)$ & $1.1932(0.1251)$ & $\ldots$ & $\ldots$ & 0.78 & 0.76 & 0.07 \\
\hline BS5 & MAYTRH90 & $-7.5760(1.6396)$ & $1.2731(0.1549)$ & $\ldots$ & $\ldots$ & 0.74 & 0.70 & 0.04 \\
\hline BS6 & $\log _{10}($ MAYRAIN $)+$ MAYRHMIN & $-31.6991(3.2600)$ & $15.3409(2.1811)$ & $0.0789(0.0394)$ & $\ldots$ & 0.91 & 0.91 & 0.54 \\
\hline BS9 & $\log _{10}($ MAYRAIN $)+$ MAYTMIN + INT2 & $-97.4831(18.5513)$ & 47.0339 (8.7337) & $7.4737(2.0367)$ & $-3.3614(0.9422)$ & 0.93 & 0.92 & 0.52 \\
\hline BS10 & $\log _{10}($ MAYRAIN $)+$ MAYRHMIN + INT1 & $-109.4841(32.3033)$ & $51.8329(15.2280)$ & $1.5463(0.6078)$ & $-0.6848(0.2831)$ & 0.92 & 0.92 & 0.65 \\
\hline BS11 & $\begin{array}{l}\log _{10}(\text { MAYRAIN })+\text { MAYRHMIN + } \\
\text { MAYTRH90 }\end{array}$ & $-31.4135(3.2772)$ & $14.9648(2.2194)$ & $0.0576(0.0454)$ & $0.1527(0.1619)$ & 0.91 & 0.91 & 0.42 \\
\hline
\end{tabular}

a Estimates of the parameters $\alpha\left(\alpha_{2}\right.$ in equation 3), the intercept parameter, and $\beta$ ( $\beta_{2}$ in equation 3$)$, the coefficient parameters, for the weather variables given in the second column.

${ }^{b}$ Linear regression models were developed based on 59 field observations. MAYRAIN = May total rainfall, MAYRHMIN = May minimum relative humidity, MAYTMIN $=$ May average daily minimum temperature, INT1 $=\log ($ MAYRAIN $) \times$ MAYRHMIN, and INT2 $=\log ($ MAYRAIN $) \times$ MAYTMIN. These variables were identified by nonparametric correlation analysis and the best-subsets procedure, except for interaction terms INT1 and INT2, which were added after variable selection. These models are meant to be used to predict the mean number of black seed per berry, conditional on its being positive.

c Pearson product-moment correlation between observed and predicted positive mean number of black seed per berry.

d Concordance correlation coefficient (CCC) was calculated as $r \times C_{b}$, where $r$ is the Pearson product-moment correlation between observed and predicted number of black seed per berry for the training data set $(\operatorname{TrD})$ and $C_{b}$ is a bias coefficient.

e CCC was calculated as $r \times C_{b}$, where $r$ is the Pearson product-moment correlation between observed and predicted number of black seed per berry for the validation data set (Val) and $C_{b}$ is a bias coefficient.

TABLE 4. Estimated parameters and corresponding standard errors (in parentheses) of 11 models (equation 3) describing the effects of weather variables on the positive percentage of diseased berries caused by Mycosphaerella fragariae

\begin{tabular}{|c|c|c|c|c|c|c|c|c|}
\hline \multirow[b]{2}{*}{ Model } & \multirow[b]{2}{*}{ Variable $^{\mathrm{b}}$} & \multicolumn{4}{|c|}{ Estimated regression parameter (corresponding standard errors) ${ }^{\mathrm{a}}$} & \multirow[b]{2}{*}{$r^{\mathrm{c}}$} & \multicolumn{2}{|c|}{$\mathrm{CCC}$} \\
\hline & & $\alpha$ & $\beta_{1}$ & $\beta_{2}$ & $\beta_{3}$ & & $\operatorname{TrD}^{\mathrm{d}}$ & $\mathrm{Val}^{\mathrm{e}}$ \\
\hline BS1 & $\log ($ MAYRAIN $)$ & $-110.6363(7.3842)$ & $59.2776(3.3745)$ & $\ldots$ & $\ldots$ & 0.92 & 0.91 & 0.62 \\
\hline BS3 & MAYRHMIN & $-28.5543(4.5734)$ & $0.9458(0.0904)$ & $\ldots$ & $\ldots$ & 0.81 & 0.79 & 0.09 \\
\hline BS4 & MJDT $>20$ & $-1.3214(2.5654)$ & $0.0408(0.0050)$ & $\ldots$ & $\ldots$ & 0.74 & 0.70 & -0.06 \\
\hline BS5 & MAYTMIN & $-9.7514(3.5829)$ & $3.4261(0.4203)$ & .. & $\ldots$ & 0.73 & 0.70 & 0.08 \\
\hline BS6 & $\log _{10}($ MAYRAIN $)+$ MAYRHMIN & $-103.9405(9.54558)$ & $53.2887(6.3865)$ & $0.1274(0.1155)$ & $\ldots$ & 0.92 & 0.92 & 0.56 \\
\hline BS9 & $\log _{10}$ (MAYRAIN) + MAYRHMIN + INT1 & $-601.4858(73.1819)$ & $286.7068(34.4984)$ & $9.5141(1.3768)$ & $-4.3803(0.6413)$ & 0.96 & 0.96 & 0.71 \\
\hline BS10 & $\log _{10}($ MAYRAIN $)+$ MAYTMIN + INT2 & $-407.9900(44.4607)$ & 198.7499 (20.9315) & $32.6597(4.8812)$ & $-15.2060(2.2582)$ & 0.96 & 0.95 & 0.64 \\
\hline BS11 & $\begin{array}{l}\log _{10}(\text { MAYRAIN })+\text { MAYRHMIN + } \\
\text { MAYTMIN }\end{array}$ & $-108.5326(10.3087)$ & $55.5380(6.6564)$ & $0.2175(0.1389)$ & $-0.5794(0.5001)$ & 0.92 & 0.92 & 0.60 \\
\hline
\end{tabular}

${ }^{a}$ Estimates of the parameters $\alpha\left(\alpha_{2}\right.$ in equation 3), the intercept parameter, and $\beta$ ( $\beta_{2}$ in equation 3$)$, the coefficient parameters, for the weather variables given in the second column.

${ }^{\mathrm{b}}$ Linear regression models were developed based on 59 field observations. MAYRAIN = May total rainfall, MAYRHMIN = May minimum relative humidity, MJDT $>20=$ May and June duration when temperature $>20^{\circ} \mathrm{C}$, MAYTMIN $=$ May average daily minimum temperature, INT1 $=\log ($ MAYRAIN $) \times$ MAYRHMIN, and INT2 $=\log ($ MAYRAIN $) \times$ MAYTMIN. These variables were identified by nonparametric correlation analysis and the best-subsets procedure, except for interaction terms INT1 and INT2, which were added after variable selection. These models are meant to be used to predict the percentage of diseased berries, conditional on it being positive.

c Pearson product-moment correlation between observed and predicted positive percentage of diseased berries.

${ }^{\mathrm{d}}$ Concordance correlation coefficient (CCC) was calculated as $r \times C_{b}$, where $r$ is the Pearson product-moment correlation between observed and predicted percent diseased berries for the training data set $(\mathrm{TrD})$ and $C_{b}$ is a bias coefficient.

e CCC was calculated as $r \times C_{b}$, where $r$ is the Pearson product-moment correlation between observed and predicted percent diseased berries for the validation data set (Val) and $C_{b}$ is a bias coefficient. 
This study had two incentives: first, to address the needs of strawberry growers to reduce their use of fungicides and increase berry yields in terms of both quantity and quality, and second, to improve our understanding of BSD epidemiology. In this study, field data were analyzed to identify weather conditions that favor BSD outbreak, severity, and incidence. Given what is known about the life cycle of $M$. fragariae (Fall 1951; Fulton 1958; Maas 1987; Nemec 1972; Paulus 1990), it was hypothesized that BSD could occur only under high leaf disease pressure, when inoculum is high, meaning after several infection-sporulation cycles. Based on available information on the relationship between weather conditions and both infection and sporulation of $M$. fragariae on leaves (Carisse and Peyrachon 1999; Carisse et al. 2000; Elliott 1988), it was anticipated that mean daily temperature would play a major role in BSD development. However, despite the variation in May mean daily temperature, which ranged from 10.44 to $16.11^{\circ} \mathrm{C}$, and June mean daily temperature, which ranged from 15.48 to $21.36^{\circ} \mathrm{C}$, temperature and temperature-related variables did not allow for separation between farm-years with and without BSD (outbreak). Much wider variations were observed in May rainfall, which ranged from 36.0 to $265.4 \mathrm{~mm}$, and June rainfall, which ranged from 51.15 to $273.0 \mathrm{~mm}$. Accordingly, May rainfall was the most influential

TABLE 5. Estimated parameters and corresponding standard errors (in parentheses) in two nonlinear regression models (equation 4), one describing the effect of total rainfall $(\mathrm{mm})$ in May (MAYRAIN) on the positive mean number of black seed (BS) and the other describing the effect of MAYRAIN on the positive percentage of diseased berries (Pdis) caused by Mycosphaerella fragariae

\begin{tabular}{|c|c|c|c|c|c|}
\hline \multirow[b]{2}{*}{ Model } & \multirow[b]{2}{*}{ Model equation $^{\mathrm{b}}$} & \multicolumn{3}{|c|}{ Estimated regression parameter (corresponding standard errors) ${ }^{\mathrm{a}}$} & \multirow[b]{2}{*}{$r^{\mathrm{c}}$} \\
\hline & & $\theta_{1}$ & $\theta_{2}$ & $\theta_{3}$ & \\
\hline BS12 (for BS) & $\theta_{1}+\theta_{2}\left\{1-\exp \left[-\theta_{3}(\right.\right.$ MAYRAIN -100$\left.\left.)\right]\right\}$ & $0.7997(0.3858)$ & $8.3831(0.4258)$ & $0.0221(0.0033)$ & 0.94 \\
\hline PD12 (for Pdis) & $\theta_{1}+\theta_{2}\left\{1-\exp \left[-\theta_{3}(\right.\right.$ MAYRAIN -100$\left.\left.)\right]\right\}$ & $1.5334(0.9083)$ & $26.6685(0.9337)$ & $0.0280(0.0024)$ & 0.97 \\
\hline
\end{tabular}

a Estimates of $\theta_{1}$, the intercept parameter; $\theta_{2}$, which can be described as the difference between the intercept and the asymptote; and $\theta_{3}$, the rate parameter.

b Nonlinear regression models were developed based on 59 field observations. The mean function (equation 4) was proposed by Parks (1982) for modeling growth. Models only include predictor MAYRAIN, from which a value of 100 was subtracted. These models are meant to be used to predict the BS or Pdis, conditional on their being positive.

c Pearson product-moment correlation between observed and predicted values of the severity variable.
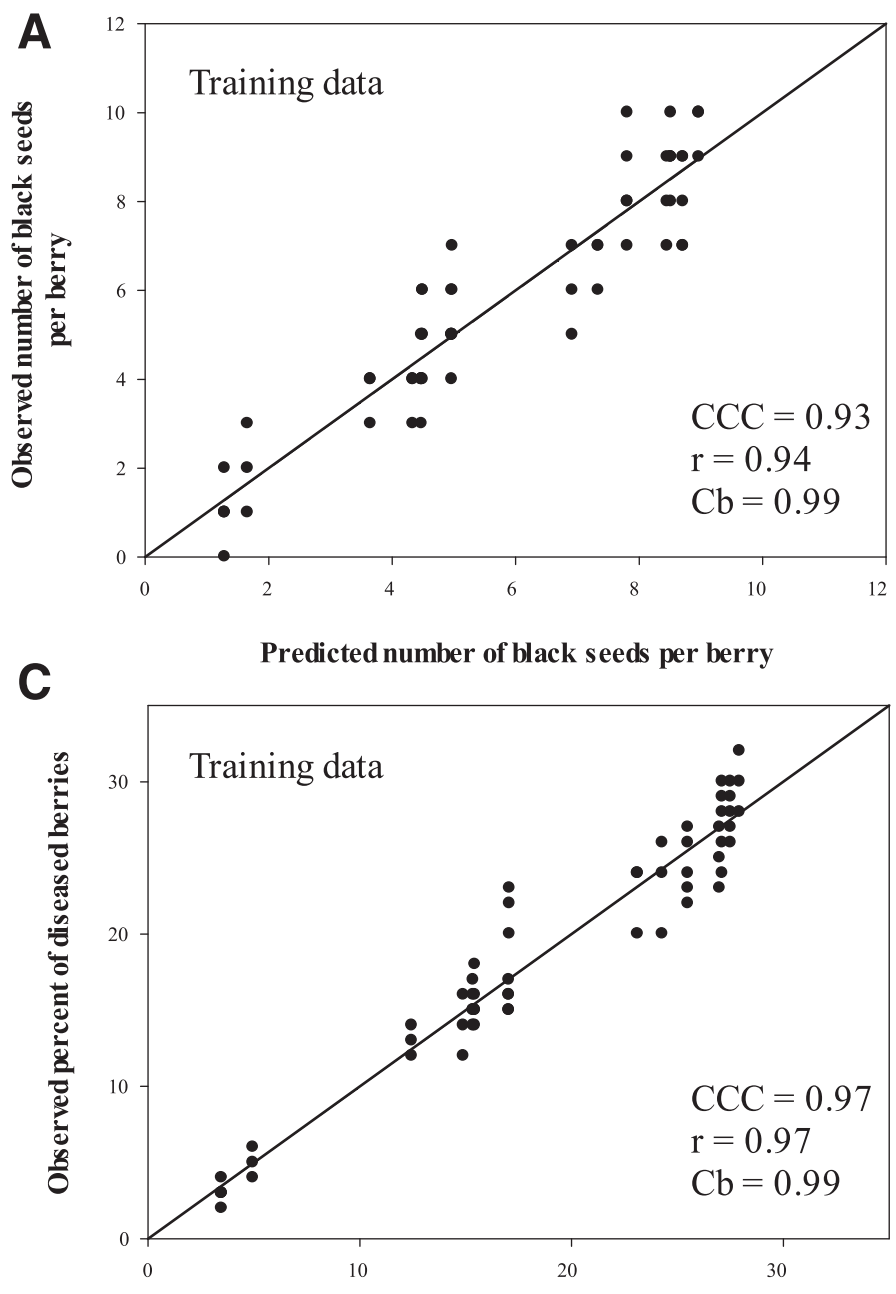

Predicted percent of dis eased berries

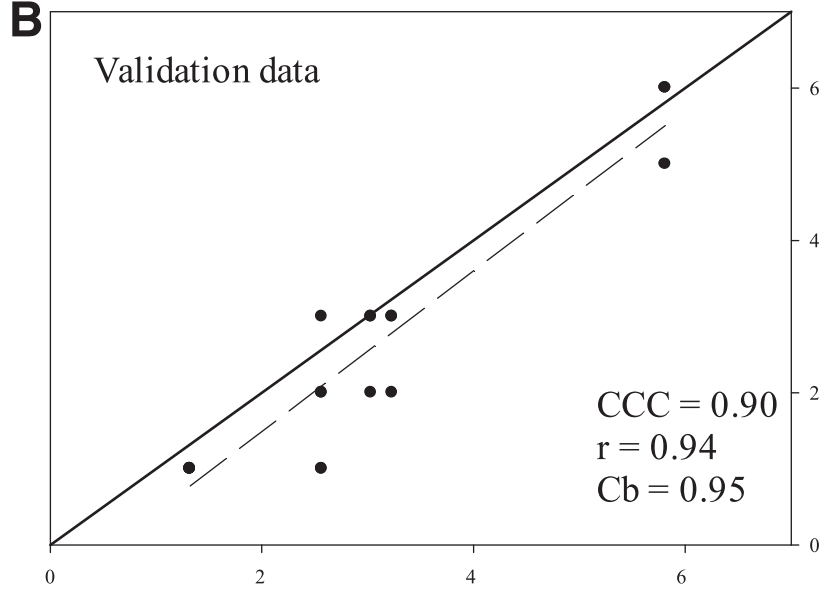

Predicted number of black seeds per berry
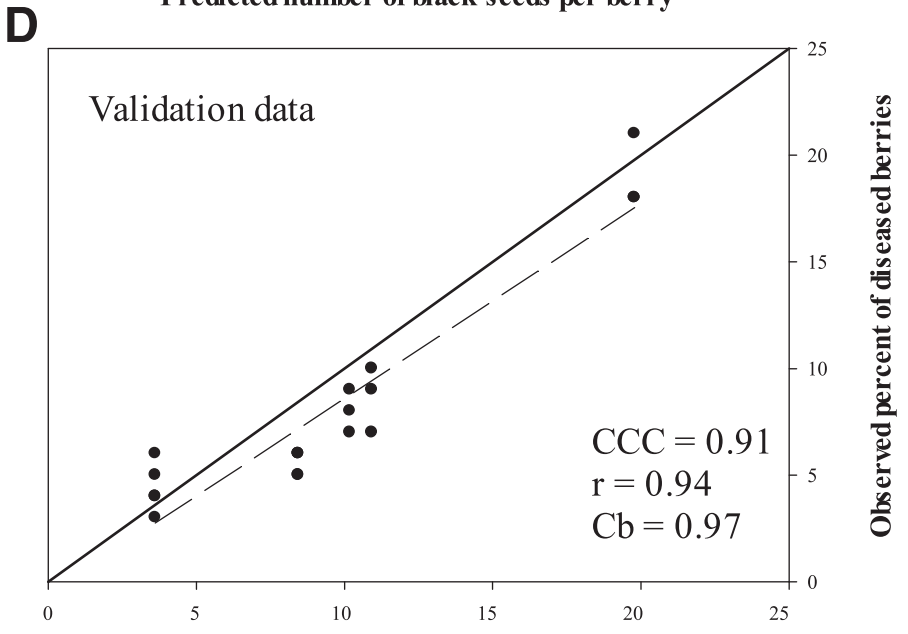

Fig. 4. Relationship between the observed and predicted $\mathbf{A}$ and $\mathbf{B}$, number of black seed per berry and $\mathbf{C}$ and $\mathbf{D}$, percentage of diseased berries. Observations in $\mathrm{A}$ and $\mathrm{C}$ are from the training data set (40 farm-years) and in B and D from the validation data set (10 farm-years). Solid and broken lines represent the concordance and best-fit lines, respectively. 
weather variable for both BSD epidemic occurrence and BSD severity and incidence.

These results are in accordance with studies conducted under controlled conditions on the influence of wetness duration on infection and sporulation, which showed that at temperatures between 5 and $30^{\circ} \mathrm{C}$, more than $24 \mathrm{~h}$ of leaf wetness is required for leaf infection and sporulation (Carisse and Peyrachon 1999; Carisse et al. 2000). Under field conditions, $24 \mathrm{~h}$ of leaf wetness can occur only if rains are frequent and dews last for most of the day. In eastern Canada, these conditions occur mostly in the spring, which explains why the amount of rain in May was the variable that best separated years with and without BSD outbreaks. Based on the results of this study, the probability of BSD occurring was near zero when the amount of rain during May was $<103 \mathrm{~mm}$ (Fig. 3). For growers with zero tolerance of BSD, the amount of rain in May could be used as a risk indicator for deciding whether or not to initiate a fungicide spray program. For growers who can tolerate some level of disease, the amount of rain above the threshold of $103 \mathrm{~mm}$ can be used as a variable in the nonlinear models developed in this study to estimate the percentage of infected berries and the number of black seed per berry (Fig. 5). Based on the nonlinear models, above the rainfall threshold of $103 \mathrm{~mm}$, the number of black seed and percentage of diseased berries increased rapidly as rainfall increased from 103 to approximately $180 \mathrm{~mm}$, and then at a slower rate as rainfall increased from $180 \mathrm{~mm}$ to the maximum observed value of $265 \mathrm{~mm}$ (Fig. 5). Considering that, in eastern Canada, flowering typically begins in early June, it would be possible to use the model developed
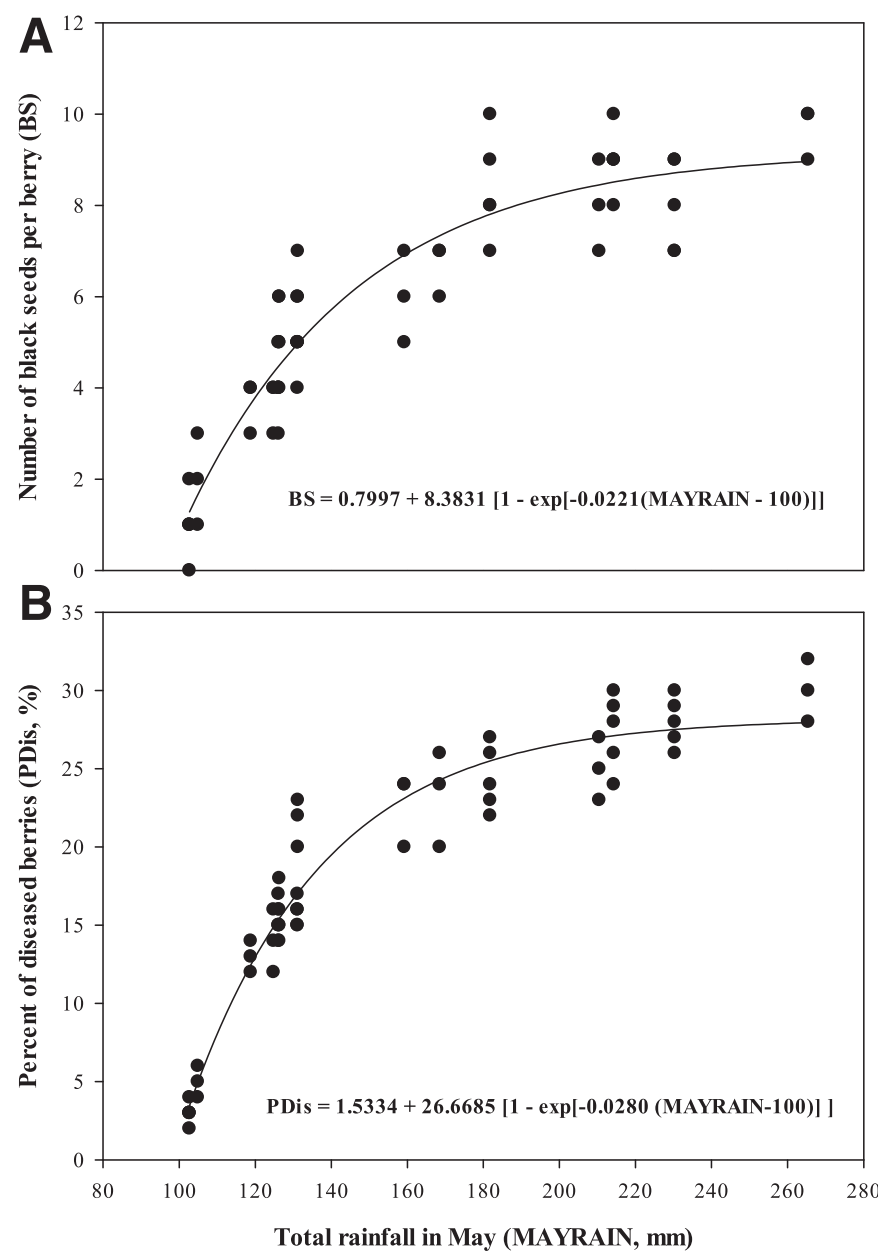

Fig. 5. Relationship between the observed and predicted A, number of black seed per berry and $\mathbf{B}$, percentage of diseased. Data were collected in 186 strawberry fields between 2000 and 2011 and predicted values were calculated using equation 4 . in this study based on rain accumulated and rain forecast during the month of May to decide whether or not flowers should be protected with a fungicide.

In this study, field observations were used to develop empirical models. The models were developed with a large data set and proved to be reliable when tested with independent data (that had not been used to develop the models). Empirical models developed from field observations tend to be robust because data generally encompass numerous sources of variations, such as cultivar susceptibility, level of inoculum, cultural practices, or production year. Hence, this type of model is suitable for estimating the risk of disease but not for drawing inferences about disease development. Considering that rain-related variables were the most significant variables for BSD occurrence and development, it can be hypothesized that rain plays a major role in completing several BSD cycles, such as spore dispersal, infection, and sporulation. Nevertheless, more knowledge about $M$. fragariae flower and berry infection pathways is required to fully understand BSD progress and to develop optimal management practices, including sanitation, cultural practices, and fungicide application. Because the leaf phase of the disease (common leaf spot) generally begins soon after bud break, the disease severity on leaves could probably be used as an additional indicator of BSD, provided that the relationship between the disease on leaves and berries is established. Furthermore, very little information is available on BSD economic thresholds or tolerance levels. Considering that the area under infected seed generally remains dry, one or two black seed on a berry could probably be acceptable; however, it is not currently known whether infected seed and the surrounding area are more prone to other diseases such as gray mold.

This study represents a first step toward better management of BSD. The disease risk indicators and models for disease severity and incidence could be used to eliminate unnecessary fungicide applications (i.e., in dry springs) and to combine the risk of BSD and gray mold when making decisions related to fungicide application during the prebloom and bloom periods.

\section{ACKNOWLEDGMENTS}

We thank A. Lefebvre and D. Rolland for their technical assistance and the strawberry growers who agreed to let us collect data on their farms. This work was financially supported by Agriculture and Agri-Food Canada.

\section{LITERATURE CITED}

Carisse, O., Bourgeois, G., and Duthie, J. A. 2000. Influence of temperature and leaf wetness duration on infection of strawberry leaves by Mycosphaerella fragariae. Phytopathology 90:1120-1125.

Carisse, O., and Maas, J. 2005. Strawberry diseases. Pages 99-118 in: Les fraisiers de chez nous [Our Strawberries]. S. Khanizadeh and J. DeEll, eds. Agriculture and Agri-Food Canada, Saint-Jean-sur-Richelieu, QC, Canada.

Carisse, O., and Peyrachon, B. 1999. Influence of temperature, wetness duration and cultivar on sporulation of Mycosphaerella fragariae on detached strawberry leaves. Can. J. Plant Pathol. 21:276-283.

CPVQ. 1992. Petits fruits: Guide de protection 1992-1993. Conseil des production végétales du Québec (CPVQ) Publ. AGDEX 230/605. Ministère de l'agriculture du Québec, Quebec City, QC, Canada.

Cragg, J. G. 1971. Some statistical models for limited dependent variables with application to the demand for durable goods. Econometrica 39: 829-844.

Dale, J. L., and Fulton, J. P. 1957. Severe loss from strawberry leaf spot in Arkansas in 1957. Plant Dis. Rep. 41:681-682.

Delhomez, N., Carisse, O., Lareau, M., and Khanizadeh, S. 1995. Susceptibility of seventeen selected strawberry cultivars and six advanced selections to leaf spot caused by Mycosphaerella fragariae. HortScience 30:592-593.

Dudley, W. R. 1889. The strawberry leaf blight. Cornell Univ. Agric. Exp. Stn. Bull. 14:171-183.

Elliott, V. J. 1988. Response models for conidiospore germination and germ tube elongation of Mycosphaerella fragariae as influenced by temperature and moisture. Phytopathology 78:645-650.

Fall, J. 1951. Studies on fungus parasites of strawberry leaves in Ontario. Can. J. Bot. 29:299-315. 
Fulton, R. H. 1958. Studies on strawberry leaf spot in Michigan. Mich. Exp. Stn. Q. Bull. 40:581-588.

Gossen, B. D., Carisse, O., Kawchuk, L., Van Der Heyden, H., and McDonald, M. R. 2014. The changing landscape of fungicide insensitivity in crop pathogens in Canada. Can. J. Plant Pathol. 36:327-340.

Janick, J., and Williams, E. B. 1959. Resistance of strawberry varieties and selections to leaf spot and scorch. Plant Dis. Rep. 43:413-415.

Khanizadeh, S., Lareau, M., and Buszard, D. 1993. Strawberry cultivar evaluation in Quebec. J. Small Fruit Vitic. 1:23-36.

Maas, J. L., ed. 1987. Compendium of Strawberry Diseases. American Phytopathological Society Press, St. Paul, MN.

Madden, L. V., Hughes, G., and van den Bosch, F. 2007. The Study of Plant Disease Epidemics. American Phytopathological Society Press, St. Paul, MN.

Marcoux, A. 1996. Effet de la tache commune sur la photosynthèse et les rendements du fraisier. M.Sc. thesis, Laval University, Quebec, QC, Canada.

Min, Y. and Agresti, A. 2002. Modeling nonnegative data with clumping at zero: A survey. J. Iran. Stat. Soc. 1:7-33.
Nemec, S. 1971. Studies on resistance of strawberry varieties and selections to Mycosphaerella fragariae in southern Illinois. Plant Dis. Rep. 55:573-576.

Nemec, S. 1972. Temperature effects on Mycosphaerella fragariae and strawberry leaf spot development. Plant Dis. Rep. 56:345-348.

Noll, S. L., Waibel, P. E., Cook, R. D., and Witmer, J. A. 1984. Biopotency of methionine sources for young turkeys. Poult. Sci. 63:2458-2470.

OMAFRA. 1996. Fruit production recommendations 1996-1997. Ontario Ministry of Agriculture, Food and Rural Affairs (OMAFRA) Publ. 360.

Parks, J. R. 1982. A Theory of Feeding and Growth of Animals. Springer Berlin Heidelberg, Heidelberg, Germany.

Paulus, A. O. 1990. Fungal diseases of strawberry. HortScience 25:885-889.

Plakidas, A. G. 1934. The mode of infection of Diplocarpon earliana and Mycosphaerella fragariae. Phytopathology 24:620-634.

Plakidas, A. G., ed. 1965. Strawberry Diseases. Louisiana State University Press, Baton Rouge.

Trelease, W. 1885. The spot disease of strawberry leaves (Ramularia tulasnei Sacc.). Ann. Rep. Wis. Agric. Exp. Stn. 2:47-58.

Weisberg, S. 2014. Applied Linear Regression, 4th ed. John Wiley \& Sons, Inc., Hoboken, NJ. 